\title{
O obstáculo irónico
}

\author{
Abel Barros Baptista e Clara Rowland
}

$E$

m 22 e 23 de novembro de 2017, decorreu na Biblioteca Nacional, em Lisboa, um colóquio sob o título O modernismo como obstáculo. Os colaboradores deste "número especial" da Luso-Brazilian Review correspondem à quase totalidade dos participantes. Os ensaios que se publicam aqui são a versão estabilizada das comunicações apresentadas no colóquio, decerto incapazes de acolher em pleno o debate que suscitaram, que foi intenso e permanente, e permanentemente intenso. ${ }^{1}$

O colóquio foi promovido pela "Rede de professores de literatura brasileira em Portugal," uma plataforma informal de cooperação, criada em 2015 por iniciativa de Osvaldo Manuel Silvestre (Universidade de Coimbra), com o propósito prático de conjugar esforços e recursos e o genérico de desenvolver os estudos literários brasileiros nas universidades portuguesas. Importa dizer que as universidades portuguesas que incluem nos curricula a literatura brasileira são apenas cinco, e os respectivos professores, pouco mais do que cinco. Acontece também que se trata de um grupo razoavelmente colaborativo e caracterizado por certa particularidade: nenhum se dedica em exclusivo aos estudos brasileiros e, na maioria dos casos, as outras áreas dos seus interesses são prioritárias do ponto de vista pessoal, institucional ou ambos.

\footnotetext{
Abel Barros Baptista é professor de literatura brasileira na Universidade Nova de Lisboa. Publicou vários livros, designadamente sobre Machado de Assis (A Formação do nome, 1991, Autobibliografias, 1998, Três emendas, 2014). O seu último livro de ensaios intitula-se E assim sucessivamente (2015).

Clara Rowland é Professora Associada no Departamento de Estudos Portugueses da Faculdade de Ciências Sociais e Humanas da Universidade Nova de Lisboa e investigadora do Instituto de Estudos de Literatura e Tradição. Desenvolve o seu trabalho nas áreas da Literatura Brasileira, da Literatura Comparada e dos Estudos Interartes. As suas publicações na área dos Estudos Brasileiros incluem ensaios sobre Guimarães Rosa, Clarice Lispector, Bernardo Carvalho, Raduan Nassar, Manuel Bandeira e Carlos Drummond de Andrade, entre outros. O seu livro A Forma do meio. Livro e narração na obra de João Guimarães Rosa foi publicado em 2011 pela Editora da Unicamp.
} 
Esta particularidade, que deixa facilmente entender-se como fragilidade de especialização, é na verdade um reforço, já que cria certa disponibilidade em relação à literatura brasileira por ser inseparável de certa distância em relação à literatura brasileira.

Talvez daí tenha resultado alguma facilidade com que se afirmou o empenho de examinar as condições do nosso trabalho de brasilianistas na universidade portuguesa. Não éramos os primeiros a fazê-lo, como é evidente; éramos porém os primeiros a fazê-lo com a possibilidade de deduzir desse exame um plano de ação articulado e a nível nacional, visto que estávamos todos, ainda que poucos, e mais ou menos unidos, ainda que desalinhados.

É claro que não se chegou nem se pretendeu chegar a plano nenhum articulado a nível nacional. O decisivo porém residia na suposição de partida, mas a necessitar de clarificação, de que o contexto português de ensino e pesquisa da literatura brasileira tem uma singularidade irredutível no exterior do Brasil. Não é aqui o momento de analisar o tópico tipicamente brasileiro dos estudos de literatura brasileira "no exterior"; mas a natureza da iniciativa que conduziu à reunião dos ensaios que agora se publicam requer compreender que o "exterior" português tem condição singular irredutível pelo facto de defrontar uma barreira única no acesso, não ao "interior" brasileiro, mas ao "exterior" previsto pelo interior brasileiro-uma barreira criada apenas para ele, como na célebre parábola de Kafka. Num sentido muito particular, essa barreira de acesso chama-se "modernismo," e é o primeiro sentido em que se pode entendê-lo como obstáculo.

Mas obstáculo a quê? E onde o defrontamos? No nosso caminho? Talvez exigindo perguntar, por exemplo, qual o caminho, se algum, para o ensino da literatura brasileira em Portugal?

Embora a ideia de obstáculo, assim definida, apenas retrospectivamente se possa considerar implicada nos trabalhos da "Rede," aquela pergunta já determinou o primeiro colóquio, realizado em Outubro de 2016, na Universidade de Coimbra, sob a designação "O conceito de literatura brasileira." A dificuldade em debate-para o qual chamámos, tal como agora, outros colegas, do Brasil e da Europa-era a impossibilidade de, na instituição universitária portuguesa, conduzir o ensino da literatura brasileira independentemente de uma interpretação da literatura brasileira gerada no processo da sua constituição enquanto literatura nacional. Se o nome do encontro citava Afrânio Coutinho, os debates acabaram atraídos para a teoria da literatura brasileira de Antonio Candido. Era já uma indicação do sentido da agenda crítica que nos conduziria ao colóquio de Lisboa, no ano seguinte, esse tal do "modernismo como obstáculo."

De facto, Antonio Candido é desde logo o autor da teoria mais bem sucedida na promoção de um "conceito de literatura brasileira": o modelo teórico 
apresentado no célebre Formação da literatura brasileira (1959), articulado com a universidade e a ideia de nação, foi e sabe-se lá se ainda não é o paradigma dominante dos estudos literários brasileiros, o mais apto a explicar a constituição da literatura brasileira como literatura nacional e o mais capaz de se articular, enquanto etapa necessária, com a continuidade formativa que ele próprio descreve. O modernismo é o ponto crítico dessa construção: Candido ofereceu a contribuição decisiva para transformar a descrição do sucesso do modernismo em descrição de todo o processo de formação da literatura brasileira. Daí que o modelo da "formação," mais do que uma descrição dominante, se tenha tornado a plataforma de encontro dos brasilianistas de todo o mundo. Estabelecido o modernismo de 22 como telos do processo em que a literatura se torna expressão da nação que se destina à nação, o século todo se torna modernista, a literatura do passado toda se torna formação, sendo que "todo" e "toda" se reconfiguram através das exclusões operadas pela descrição dominante.

Ora, uma das exclusões é particularmente conspícua: a exclusão portuguesa. Sabe-se que, desde Gonçalves de Magalhães, a constituição nacional da literatura brasileira é um projeto que estipula a exclusão da portuguesa como condição necessária da sua realização histórica. Mas foi Antonio Candido quem, em passagem célebre de um ensaio escrito em 1950, significativamente um "panorama para estrangeiros," declarou essa condição plenamente cumprida. Comparando romantismo e modernismo, dois "momentos decisivos que mudam os rumos e vitalizam toda a inteligência," Candido define nestes termos a diferença entre eles: "enquanto o primeiro procura superar a influência portuguesa e afirmar contra ela a peculiaridade literária do Brasil, o segundo já desconhece Portugal, pura e simplesmente ... Um fato capital se torna deste modo claro na história da nossa cultura; a velha mãe pátria deixara de existir para nós como termo a ser enfrentado e superado" (Antonio Candido 112).

O ponto distintivo é que a descrição do modernismo como movimento triunfante não é separável da exclusão portuguesa, a qual ora se apresenta como condição ora como resultado desse triunfo. Declaração peremptória, essa de Candido, não pode ler-se como descrição de um estado de coisas, porque vale performativamente, como testemunho de cumprimento da finalidade de superação plena do passado e, para lá disso, autorização para desconhecer "Portugal pura e simplesmente." Que seja fácil reunir evidências da parcialidade ou aliás falsidade da declaração, apenas comprova que o triunfo do modernismo é sobretudo triunfo da descrição do modernismo como movimento triunfante: e é a descrição que se impõe, que se transmite na universidade e na escola, que se normaliza em lugar-comum e, enfim, se exporta. Ao ponto de nem sempre ser claro o que se entende por modernismo, pois 
que a palavra se foi alargando para designar um movimento, uma estética, um período, aliás dois, aliás todo o século.... alcançando até o que lhe escapou ou resistiu.

Não é imediatamente claro em que medida ou por que razão isto determina a barreira única a que aludimos acima e define, em consequência, a posição única dos estudos de literatura brasileira em Portugal. Decerto que o triunfo da descrição do triunfo do modernismo pode suscitar-sabe-se, de resto, que suscitou e suscita—reações de ressentimento, afirmações da prioridade portuguesa, declarações de fé na unidade dos dois países, aglomeradas sob vários nomes conhecidos, mas sempre ancoradas no postulado da língua concebida como causa e garante de uma homogeneidade fundamental. Não é também difícil, pelo contrário, arrolar entre os efeitos dessa descrição triunfante, o de também a literatura portuguesa ignorar "pura e simplesmente" a brasileira, mesmo tendo em conta que não é seguro que possamos isolar um interesse português pela literatura brasileira anterior e imune à exclusão modernista. Seriam ambos os fenómenos, afinal, instâncias do que Eduardo Lourenço chamou o "não-laço cultural que, no plano cultural e sobretudo no da comunicação profunda, existe hoje entre Portugal e Brasil" (151).

Acreditamos, entretanto, que o problema de que falamos tem uma especificidade que resiste a diluir-se nesses episódios ou fenómenos mais falados do que conhecidos. Delimitemos, por ora, dois efeitos.

O primeiro efeito é uma subordinação quase inescapável. Se o modernismo alcança ser descrito como o movimento que alastra a todo o século e reordena a literatura brasileira, não há como evitá-lo: assumindo-o, com submissão ou distância, ou recusando-o, o modernismo tal como essa descrição o apresenta é inexorável onde quer que a literatura brasileira tenha lugar institucional delimitado no currículo universitário. Mas mais do que isso, na medida em que o fundamento do triunfo do modernismo é a expressão da nação, enquanto, como escreveu Mário de Andrade, "todo orgânico de consciência coletiva" (242), a descrição do triunfo modernista constrange a liberdade da crítica e ergue uma fronteira diante do estrangeiro, onde ostenta um grande letreiro: "Não há compreensão da literatura brasileira fora da compreensão do Brasil." O estrangeiro que, por amor ou simples interesse pela literatura criada no Brasil, se submete a este ditame, é conduzido inevitável e perversamente a menorizá-la.

O efeito de subordinação tem por sua vez outro efeito visível, e foi aliás por onde começámos: os estudos literários brasileiros existem na universidade portuguesa enquanto circunscrição rigorosamente delimitada, com pequeníssima expressão e escasso número de efetivos. Algumas obras brasileiras integram as escolhas de leitura nos planos de estudos de Português nos vários níveis de ensino, é possível encontrar alguns autores brasileiros em programas de literatura comparada, embora poucos e raramente, mas a 
literatura portuguesa continua a existir na universidade portuguesa como se fosse a única literatura em português, portanto sem prevenir a tentação de se supor aquela literatura que representa a experiência literária em língua portuguesa e diante da qual as outras seriam derivadas e menores.

A literatura brasileira mantém-se assim na universidade portuguesa com um estatuto estranho: uma literatura menorizada por efeito do próprio triunfo do processo da sua constituição em literatura nacional autónoma, uma literatura estrangeira entre outras sem poder ser uma entre outras. Seria fácil defini-la como "literatura estrangeira na mesma língua," mas não há aí nenhuma palavra que não seja problemática. Língua, por exemplo. A experiência literária brasileira oferece abundante matéria de reflexão sobre a relação entre língua e literatura; no entanto, o assunto está gritantemente descurado, apesar do papel decisivo que desempenha na descrição do triunfo modernista e na comprovação do mesmo. A miragem de língua do modernismo não foi, como tão apressadamente se repete mesmo não acreditando no que se repete, a inexequível criação de uma língua própria, mas essa outra, nem exequível, a da língua própria no interior da língua imprópria: a fala comum insinuada à força de prescrição no corpo suposto obsoleto e rígido dos puristas de ambos os lados do oceano. A diferenciação linguística foi capturada pela diferenciação nacional a ponto de ser hoje o mais paradoxal obstáculo, porque se não se livra da sugestão ou da nostalgia de uma homogeneidade cultural e literária nela fundada, atua de facto como princípio de reconhecimento imediato da diferença nacional.

Regressando então ao tópico da entrada, o modernismo ofereceu à "Rede" menos o obstáculo como barreira e obscurecimento do que o obstáculo como a oportunidade de confirmar, e disso tirar ilações radicais, que não subsiste nenhuma razão fundamental para ensinar literatura brasileira na universidade portuguesa. Nem mesmo a língua. Além disso, a oportunidade é mais radicalmente a de também confirmar que o que vale para a literatura brasileira vale para a portuguesa: não há também nenhuma razão fundamental para ensinar literatura portuguesa em Portugal, e em parte-a parte que diz respeito à língua-, em consequência da experiência brasileira. Tradição, património, povo, alma nacional, identidade, etc., são tudo nomes sobrecarregados com a missão de substituir um único, aliás menos nome do que eles: nosso. Basicamente, ensinamos literatura portuguesa e queremos que seja ensinada nas escolas porque é a literatura a que chamamos "nossa": ora, essa possibilidade de lhe chamar "nossa" esclarece-se melhor na representação concentrada da ação deliberada do modernismo brasileiro, segundo a descrição do seu triunfo, afinal dito e narrado como se fosse apenas devido justamente a ter construído a literatura a que os brasileiros podem chamar sua.

Eis uma face meio hedionda do obstáculo: por que razão, afinal, a vontade de uma literatura a que possamos chamar nossa prevalece sobre o gosto, o 
interesse ou o empenho de a partilhar com outros? A ilusão de que há uma porção da literatura que nos pertence é provavelmente constitutiva da literatura moderna; a ilusão de que essa pertença lhe concede prioridade sobre todas, as do passado e as dos outros, pode também ser exemplificada pelo modernismo brasileiro, mas não tem nação nem conteúdo nacional determinado. Essa ilusão, operando naturalizada, é que dita a urgência da revisão do modernismo: mas a urgência não deve ignorar nem esquecer que se trata de rever um exemplo de ilusão, não o único caso, não o nosso caso, não apenas o caso com que lidamos ou mesmo cujas consequências sofremos.

Encarar o modernismo como obstáculo é assim uma operação para além do modernismo brasileiro, ainda que na sua formulação original a ele tenha ficado circunscrita. Mais do que isso, é uma operação que não pode senão incluir-se a si mesma na interrogação que lança: por isso irónica, em certo sentido reconhecidamente pouco claro. De facto, seria arrogância ou pretensão tola supor que um colóquio em Lisboa removeria do caminho dos seus participantes o obstáculo de uma doxa e lhe permitiria enfim aceder ao caminho de forma correta ou até corretíssima de ensinar literatura brasileira. Ou que poderíamos interrogar o "interior" do outro num lugar seguro, imune às consequências e aos imprevistos da interrogação. Fracos leitores de Drummond, em particular do Drummond da "Máquina do mundo." Pior, fracos leitores seríamos do nosso próprio título, porque transformaríamos o obstáculo do modernismo em barreira à compreensão do próprio lugar de onde queremos afinal sair ou migrar em deslocação permanente.

A deslocação que o colóquio operou consistiu afinal em não deixar que o obstáculo se reduzisse à descrição do modernismo triunfante e à consequente definição do contexto português, apenas entendido como barreira ou impedimento que, uma vez removido, deixaria livre o acesso a outra coisa, a autêntica coisa ou a verdadeira coisa. Por isso a consideração do obstáculo, ao longo dos dois dias de trabalho, se tornou irónica. Havia um obstáculo a pairar sobre todos, e era o obstáculo indefinido gerador de obstáculos: o obstáculo pôde ser, em variação metonímica, o embaraço, o incómodo, o estorvo, o empecilho, a atrapalhação ou a dificuldade ... A série sugere que é possível conversarmos todos sobre o mesmo falando todos de coisas diferentes e nesse processo lá irmos tant bien que mal escapando aos terrenos delimitados e aos letreiros de fronteira. Na ecologia do colóquio, o obstáculo foi sendo algo perseguido, como coisa a extirpar, e ao mesmo tempo algo de que não nos queríamos livrar, porque era força de ajuntamento na discussão, ânimo e entusiasmo, por vezes simples boa disposição, largas risadas incluídas. Discutir o obstáculo tornou-se um empreendimento tão divertido como inteligente. Nesse sentido, os trabalhos do colóquio decorreram sem obstáculos, apesar de juntarem pessoas de diferentes alinhamentos, de antagónicas inclinações, e por isso mesmo decorreram também fora de contexto, 
português ou outro, ou fora do lugar, brasileiro ou outro. É claro que, ao contexto ou ao lugar, sempre se acaba por regressar. Mas enquanto se suspenderam os regressos, partilhámos um palco de controvérsia em que o obstáculo deslizou irónico.

O ensaio de Osvaldo Manuel Silvestre (Universidade de Coimbra) abriu esse deslizamento de forma eloquente a partir de um comentário da célebre resposta de Drummond, em 1942, à pergunta "O modernismo morreu?" $\mathrm{O}$ cerne do argumento de Silvestre pode surpreender-se nesta passagem: "o Modernismo é o maior obstáculo a que pensemos o Moderno, antes e depois dele; assim como o Moderno é o maior obstáculo a que consideremos o Modernismo na sua específica configuração histórica, isto é, contingente mas bastante, e não como um slot mais, vazio e saturável, na meta-história do Moderno." A partir de uma densa discussão em torno da música do Brasil modernista, de interesse mais do que estratégico, o artigo analisa com subtileza e inteligência as interações de moderno e modernismo para a partir delas deduzir o "elenco dos obstáculos."

Um "obstáculo" tão relevante como inesperado seria Flávio de Carvalho, a única das duas figuras modernistas a merecer duas comunicações (interessantemente, a outra foi Mário de Andrade). A professora Alva Teixeiro (Universidade de Lisboa), a partir de uma análise muito aprofundada e detalhada da Experiência $n^{\circ}$ 2, elabora uma interrogação instigante do lugar de Flávio de Carvalho na discussão do Modernismo no Brasil. A sugestão de um modernismo alternativo, radical e incómodo para uma visão homogénea do movimento, é construída através de aproximações ágeis e significativas com outros contextos de discussão da arte moderna (como na aproximação à "performance arte" ou na comparação com Richard Serra). Essa deslocação permite não apenas uma caracterização forte da complexidade teórica do percurso de Flávio de Carvalho enquanto percurso moderno, mas também uma revisão consistente de alguns lugares-comuns sobre o Modernismo no Brasil-entre os quais se destacam, sem dúvida, a excelente discussão da relação do modernismo e da crítica de artes modernista com a figuração em arte e a consequente interrogação do valor político tanto da ação de Carvalho quanto da sua rasura por parte de Mário de Andrade.

O mesmo Mário de Andrade surge no centro de gravidade da crítica de Marcelo Moreschi (UNIFESP), no segundo ensaio dedicado a Flávio, que leva a sério a etimologia e entende a polémica como arte de combate. Mas a feição manifestamente polémica do ensaio decorre de o autor pretender inscrevê-lo no exterior radical do que chama o "construto 'modernismo brasileiro." Flávio de Carvalho é ao mesmo tempo o exemplo que comprova o argumento 
de Moreschi e a arma que maneja no esforço de demolição do "construto." $\mathrm{Ou}$, seguindo a formulação inicial do autor-que regressa no final, como que celebrando o cumprimento de uma promessa polémica-, o ensaio pretende abordar dois obstáculos, o que quer remover, "o modernismo como obstáculo, tal como em debate hoje," e o que quer oferecer, colocar diante do anterior, "um obstáculo para o modernismo." A ação é conseguida enquanto passo de um trabalho em processo, quiçá processo sem termo previsível; e não será uma das menores qualidades do ensaio o facto de a colocação de dois obstáculos recíprocos ser-ou se pretender-ela própria carvalhiana.

Mário de Andrade é objecto de discussão com perspectivas e ênfase muito diferentes nas contribuições de Ivan Marques (USP) e Pedro Meira Monteiro (Princeton University), que constituem um segundo bloco-verdadeiro ponto nodal do dossier, tendo em conta que todas estas leituras se confrontam, de um modo ou de outro, com o lugar de Mário de Andrade no caminho modernista-desta proposta. O propósito explícito de Marques é rever críticas recentes ao modernismo paulista e, em particular, da figura e obra do autor de Macunaíma. A perspectiva da revisão é colocada sob a pergunta: "Por que, afinal, o modernismo ainda é capaz de perturbar o sono?" Atesta-se assim, por um lado, a atualidade do modernismo e, por outro, o reconhecimento da crise por que passa essa atualidade. Dir-se-ia sem dificuldade que esse paradoxo ilustra uma das acepções possíveis para entender ou designar o modernismo como um obstáculo: mas a elaboração de Marques é conduzida ao ponto de reconhecer o obstáculo no próprio cerne das contradições de Mário de Andrade, ou melhor de constituir essas contradições em obstáculo a uma visão unificada de Mário, em vez da "centralidade extravagante" de "um movimento dialético que incorpora dificuldades e não se esquiva de contradições." A revisão das críticas recentes ao modernismo é assim orientada para a recusa de visões redutoras e monolíticas do modernismo, clichés, segundo o autor, e valorização crítica das contradições e paradoxos que afetam a obra de Mário de Andrade.

Já Pedro Meira Monteiro procede a uma revisitação da obra de Mário de Andrade através de um ângulo decisivo na avaliação do seu papel e da sua obra no modernismo brasileiro: nos termos do autor, "o inescapável dilema do indivíduo diante da voz coletiva." A reflexão é muito estimulante e repõe em renovados termos uma das tensões conhecidas e aliás constitutivas do escritor modernista, e no caso brasileiro um fundamento do sentido da nacionalidade. $\mathrm{O}$ autor não encara abertamente o problema da nacionalidade, pelo contrário procura situar essa tensão numa tradição mais vasta e com raízes designadas até Rousseau. Mas é indiscutível que a análise proposta e em particular as interrogações deixadas no termo, ancoradas na situação política recente brasileira ("fica em aberto o significado político de uma concepção do indivíduo que o tem como uma espécie de obstáculo para a afirmação da 
coletividade"), se revelam muito fecundas para pensar a relação de Mário de Andrade com noções como povo, comunidade ou cultura nacional. A figura de Mário de Andrade desenhada no artigo é assim ao mesmo tempo tradicional e renovada: é o mesmo Mário enquanto expressão de um movimento que o precede e antecede, mas ainda o mesmo Mário em conflito ou tensão com esse movimento.

$\mathrm{Na}$ terceira parte do dossier, a discussão em torno do obstáculo altera-se, ou desliza, para outro tipo de configuração, que comprova, acreditamos, a validade do enquadramento proposto. Menos centrados sobre uma reavaliação do movimento a partir dos seus lugares e atores, os ensaios desta secção fazem do obstáculo uma plataforma elástica, tão indefinida quanto produtiva, para a releitura original, a partir de novas constelações, de alguns dos autores modernistas fundamentais. Oswald de Andrade esteve a cargo de Eduardo Sterzi (UNICAMP), que contribui com um ensaio que apresenta uma leitura transversal da sua obra a partir de um quadro teórico amplo e produtivo que, desativando algumas das ligações mais recorrentes entre o percurso de Oswald e a evolução do movimento modernista brasileiro, resulta numa visão atualizada (e muito pertinente para o debate em curso no conjunto de ensaios) da modernidade da proposta implícita nesta obra. Considerando as noções de lei e excepcionalidade em Kafka, Benjamin e Agamben, o texto interroga o valor da expressão "fora da lei" nas várias dimensões da produção de Oswald: a língua, a dimensão nacional do projeto literário, a tradição, a articulação entre poemas e manifestos, a política. Particular destaque ganham o questionamento das leituras correntes do estatuto do primitivo no "Manifesto antropófago" (feito à luz de Viveiros de Castro) e do valor da infância como negação adulta da norma na obra oswaldiana. $\mathrm{O}$ ensaio propõe assim ao mesmo tempo um mapeamento original da articulação entre alguns conceitos-chave da obra de Oswald ao longo dos anos e uma releitura relevante e inovadora da reflexão teórica que esta representa.

O ensaio de Clara Rowland (Universidade Nova de Lisboa) sobre Manuel Bandeira opera um gesto tão inesperado como afinal indispensável: conduzir ao interior da obra poética de Bandeira o ofício de antologiador a que se dedicou incansavelmente. A autora consegue persuadir-nos de que o exercício da composição de antologias é na verdade a exposição clara das operações fundamentais da sua poética: "Nas antologias próprias . . . Bandeira seleciona, reorganiza, reorienta, na verdade reinstaurando uma figura-a da disposição seletiva enquanto figuração e desfiguração da obra-ativa em todos os seus livros." A elaboração do argumento é frequentemente surpreendente, nunca perdendo de vista o texto do poeta, quer o texto dos poemas assim compostos, quer o texto em que se explica sobre os poemas assim compostos. O alcance deste ensaio, considerando a posição fixa em que se mantém a 
poesia de Bandeira na constelação modernista, é o alcance próprio do efeito de "desconstelizar-se," para usar a palavra do próprio Bandeira que a autora recupera para o lançamento do seu texto e que afinal é outra metáfora do deslizamento do obstáculo.

Joana Matos Frias (Universidade do Porto) tomou em mãos o "caso Drummond," que revê respondendo à proposição que serviu de mote para o colóquio e para o dossier em causa: por um lado, compõe um mapa extremamente detalhado e compósito da rede de relações que fazem do modernismo, e sobretudo das implicações nacionalistas e colectivistas da sua versão mais canónica, um obstáculo para Drummond; por outro, constrói um retrato da obra de Drummond (e da vinculação dessa obra ao retrato de Drummondcomo na questão da assinatura, ou no destaque para as figuras do nascimento poético como grau zero desta poesia) como obstáculo para qualquer retrato do Modernismo que se queira homogéneo. A figura do conflito, central na poética drummondiana, articula as diferentes linhas de leitura deste problema e a afirmação de uma recusa das dimensões "épicas" da constituição do Modernismo, possibilitando à leitura proposta uma incidência sobre o conjunto da obra que permite o estabelecimento de diálogos menos óbvios com outros poetas e contraria as habituais divisões da obra de Drummond em fases ou períodos de difícil conciliação.

A fechar o conjunto, Gustavo Rubim (Universidade Nova de Lisboa) enriquece a controvérsia do obstáculo com um nome ele próprio também obstáculo a unificações homogeneizantes: Jorge de Lima. Com grande concisão, precisão e contundência, o curto estudo apresenta um ambicioso programa de revisão crítica dos efeitos de uma obra como A invenção de Orfeu sobre ideias estabelecidas do modernismo brasileiro, primeiro, e do moderno em poesia depois. Essa revisão assenta na identificação de uma excepcionalidade/extravagância constitutiva do programa estético da obra de Jorge de Lima que se revela através das sucessivas tentativas de circunscrição por parte da crítica modernista. Infrutíferas na tentativa de "agarrar o monstro," para usar a expressão de Murilo que alimenta o ponto de partida do ensaio, essas tentativas fazem ressaltar a força de resistência de uma obra inclassificável precisamente através da sua inclusão excepcional no panorama modernista. A figura do mapa, convocada inicialmente, é por isso determinante: a desestruturação cartográfica atribuída à perturbação das coordenadas históricas e espaciais do poema de Jorge de Lima é, também, estratégia do ensaio ao construir-se sobre dois movimentos de "obscurecimento do moderno" que a obra de Lima ativa, e que se revelam eixos definidores de um mapa que, assim desestruturados, só podem sustentar por negação. É, neste sentido, um dos contributos decisivos para uma interrogação do modernismo a partir do seu interior-o lugar e a leitura de Murilo e Jorge de Lima no mapa modernista—, mas, também, a partir da exterioridade radical que a extravagância 
anacrónica desta obra, verdadeiro obstáculo no meio do caminho, necessariamente convoca. Neste duplo movimento-mapeamento, deslizamentoreside também, acreditamos, o alcance desta proposta conjunta de releitura do modernismo brasileiro.

\author{
Abel Barros Baptista \\ Universidade Nova de Lisboa \\ Instituto de Estudos de Literatura e Tradição \\ Avenida de Berna, 26 C - Lisboa, Portugal \\ abb@fcsh.unl.pt \\ Clara Rowland \\ Universidade Nova de Lisboa \\ Instituto de Estudos de Literatura e Tradição \\ Avenida de Berna, 26 C - Lisboa, Portugal \\ clararowland@gmail.com
}

\title{
Notas
}

1. O Modernismo como obstáculo. Colóquio Internacional. Instituto de Estudos de Literatura e Tradição (IELT), Faculdade de Ciências Sociais e Humanas (FCSH) da Universidade Nova de Lisboa (UNL). 22 e 23 de novembro de 2017, Biblioteca Nacional de Portugal. Participantes: Abel Barros Baptista (UNL/IELT), Alfredo César Melo (UNICAMP), Alva Teixeiro (FLUL), Clara Rowland (UNL/IELT), Eduardo Sterzi (UNICAMP), Gustavo Rubim (UNL/IELT), Ivan Marques (USP), Joana Matos Frias (FLUP), José Miguel Wisnik (USP), Marcelo Moreschi (UNIFESP), Osvaldo Manuel Silvestre (FLUC), Pedro Meira Monteiro (Princeton University). A Rede de Professores de Literatura Brasileira em Portugal, a que se alude no parágrafo seguinte, foi criada em 2015, na Universidade de Coimbra, e dela fazem parte: Abel Barros Baptista (Universidade Nova de Lisboa), Alva Teixeiro (Universidade de Lisboa), Carlos Mendes de Sousa (Universidade do Minho), Clara Rowland (Universidade Nova de Lisboa), Francisco Topa (Universidade do Porto), Joana Matos Frias (Universidade do Porto), Osvaldo Manuel Silvestre (Universidade de Coimbra).

\section{Obras citadas}

Andrade, Mário de. Aspectos da literatura brasileira. São Paulo: Livraria Martins, 1974.

Candido, Antonio. Literatura e sociedade. Estudos de teoria e história literária. São Paulo: T. A. Queiroz, 2002.

Lourenço, Eduardo. A nau de Ícaro seguido de Imagem e miragem da lusofonia. Lisboa: Gradiva, 2004. 